\title{
Effectiveness of Mass Rabies Dog Vaccination Campaign in Communes V and VI of the Bamako-Mali, District
}

\author{
Ibrahim Sow ${ }^{1,2}$, Yaya Sidi Koné2, Kadiatou Coulibaly ${ }^{2}$, Marthin Dakouo², Satigui Sidibé \\ Amadou Hamadoun Babana ${ }^{1}$, Mamadou Niang ${ }^{2}$ \\ ${ }^{1}$ Department of Biology, Faculty of Sciences \& Techniques, University of Sciences, Techniques and Technologies, Bamako, Mali \\ ${ }^{2}$ Diagnosis and Research Service, Central Veterinary Laboratory, Bamako, Mali
}

\section{Email address:}

sowbreham@gmail.com (I. Sow), yayasidikone@yahoo.fr (Y. S. Koné), welecoulibaly@yahoo.fr (K. Coulibaly), dakouo@gmail.com (M. Dakouo), sidibsatigui@gmail.com (S. Sidibé), ahbabana@laborem-biotech.com (A. H. Babana), mniangm@yahoo.fr (M. Niang)

\section{To cite this article:}

Ibrahim Sow, Yaya Sidi Koné, Kadiatou Coulibaly, Marthin Dakouo, Satigui Sidibé, Amadou Hamadoun Babana, Mamadou Niang. Effectiveness of Mass Rabies Dog Vaccination Campaign in Communes V and VI of the Bamako-Mali, District. International Journal of Animal Science and Technology. Vol. 3, No. 2, 2019, pp. 30-34. doi: 10.11648/j.ijast.20190302.12

Received: June 20, 2019; Accepted: July 22, 2019; Published: August 6, 2019

\begin{abstract}
Canine rabies remains an important public health problem in Africa. Mass vaccination of dogs is the recommended method for the control and elimination of rabies. We report the second free mass vaccination campaign of the dog in the communes V and VI of the district of Bamako that took place in September 2014. The objective was to estimate vaccination coverage by evaluating the effectiveness of the vaccination campaign and to determine the effectiveness parameters of the intervention by the capture mark recapture method and the Bayesian model. In commune V, vaccination coverage was $27 \%$ with a canine population estimated at 1531 and the proportion of dogs without owners was $2 \%$. For commune VI, the canine population was estimated at 3510 with a vaccination coverage of $20 \%$. The proportion of the nonowner dog population was $8 \%$. The final effectiveness was $33 \%$ and $28 \%$ respectively in communes V and VI. Availability has been identified as the most sensitive effectiveness parameter attributed to the lack of campaign information. Despite low immunization coverage, it is possible to carry out vaccination campaigns that had an impact in Bamako district. For higher immunization coverage, a vaccination strategy adapted locally, perhaps, through a combination of fixed-line immunization and door-to-door vaccination.
\end{abstract}

Keywords: Vaccination Campaign, Canine Rabies, Bamako District, Efficacy

\section{Introduction}

Canine rabies remains an important public health problem [1]. An estimated 60,000 human cases occur each year [2] and most of these occur in Asia and Africa [3]. The causal agent is a virus of the lyssavirus genus, usually transmitted to humans by the bite of a rabid animal through saliva [4-5].

Rabies is prevalent in all continents [5]. Only a few countries like Great Britain, Japan, Australia and the Pacific Islands are free of the disease [4]. In Africa, no country has been reported as free from rabies and in West Africa the disease persists in an enzootic state [6]. The incidence of the disease has increased in some countries of this continent [7]. Children under 15 [8] are particularly exposed [9, 10, 11].
The disease is most prevalent in underserved communities with limited access to the health system and veterinary medicine [12]. In Mali, 16 cases of human rabies were reported from January 2013 to September 2013 [8] and rabid dogs are responsible for the majority of these cases [13].

Rabies control is one of the priorities of the World Health Organization, which has set a goal of reducing the number of deaths from human life linked to this disease by 2030. The success of rabies control relies on community participation, access to mass vaccination of dogs and access to postexposure treatment. To be in this dynamic, Mali with the support of technical partners has initiated a mass vaccination campaign for dogs and its evaluation.

The objective of the present study was to conduct a test vaccination campaign against canine rabies in communes $\mathrm{V}$ 
and VI, to evaluate vaccination coverage through efficiency parameters as well as community participation.

\section{Material and Methods}

\subsection{Study Zone}

The study was conducted in the district of Bamako, economic and political capital of Mali with $1,800,000$ inhabitants [14] and more precisely in communes V and VI.

Commune $\mathrm{V}$ covers an area of $41 \mathrm{~km}^{2}$. It is bounded on the North by the Niger River, on the South by the airport zone and the rural commune of Kalanban-Coro, on the East by Commune VI. It is composed of seven districts: Badalabougou, Mali District, Torokorobougou, BacoDjicoroni, Sabalibougou, Daoudabougou and Kalaban-Coura and has 413,266 inhabitants [14].

According to the monograph of the district of Bamako, commune VI has a surface of $88,82 \mathrm{Km}^{2}$. It is the largest commune in the district of Bamako. Its population is estimated at 469,653 inhabitants [14]. It consists of ten districts: Banankabougou, Dianékéla, Faladiè, Magnambougou, Missabougou, Niamakoro, Sénou, Sogoniko, Socorodji and Yrimadio.

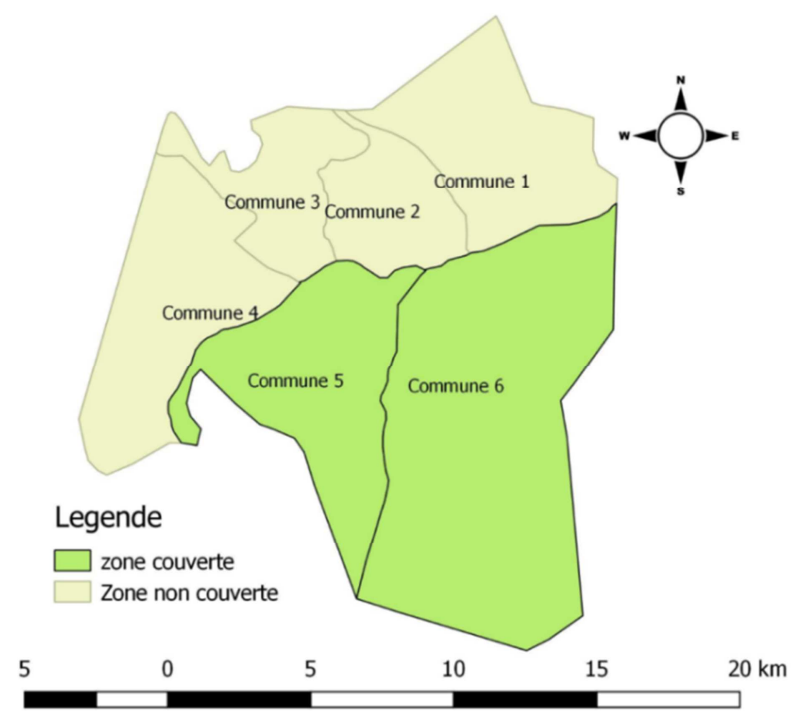

Figure 1. Map of the study area.

\subsection{Vaccination Campaign}

In both communes, fixed immunization posts were strategically placed in all quarters for five consecutive days, where dog owners could bring their dogs for free rabies vaccination. In Commune V, 19 posts were identified in the seven districts, while in Commune VI, 24 fixed posts were identified in the ten quarters by their district chiefs.

Each vaccination team consisted of two people, including at least one veterinarian for the actual vaccination.

The materials used during this campaign were chairs, a table and vaccination cards signed by the chief veterinary sector of the commune, single-use syringes, registers, markers, green necklaces, a first aid kit rescue, a plastic bin, scissors, muzzle and Rabisin vaccine. Each morning, five (5) flasks of Rabisin vaccine (Rabisin ${ }^{\circledR}$ Merial type) of $10 \mathrm{ml}$ per vial are deposited at the vaccination station stored in an ice-cold box. Vaccination began at 8 am and ended at $4 \mathrm{pm}$.

The vaccination campaign took place for 5 consecutive days in each municipality, from September 6, 2014. The campaign financed by the Swiss cooperation through the Swiss TPH (Tropical Public Health) provided 8000 doses of Rabisin ${ }^{\circledR}$ vaccine of the firm Merial with so many green necklaces and vaccination cards. Each dog brought to the vaccination post was vaccinated free of charge using $1 \mathrm{ml}$ of Rabisin $\AA$. The description of the dog (dress, age and address of the owner) is recorded in the register. Finally, each vaccinated $\operatorname{dog}$ is marked using a green collar and a vaccination card is issued to the dog owner.

When the frequency decreased on the second or third day, some vaccination teams began to vaccinate door to door around their vaccination posts.

\subsection{Transect Study}

In each commune, a transect line was determined on the basis of geographical coordinates. This transect was conducted in a vehicle with three observers to count the number of marked and unlabeled dogs in the street. This transect lasted two consecutive days in each commune and was as follows: an early morning and a late morning.

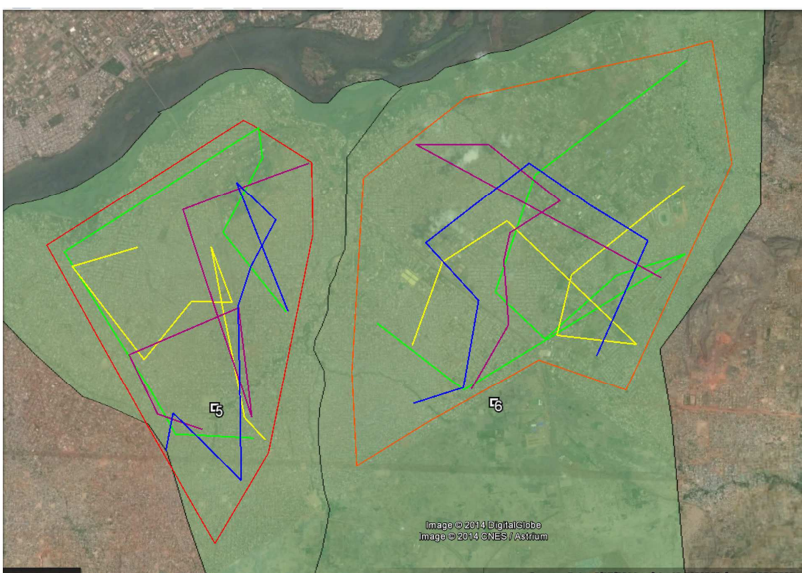

Figure 2. Line observed during the transect.

\subsection{Household Survey}

To evaluate the different parameters of effectiveness, a household survey was organized the day after the five days of vaccination. A survey of households with at least one dog was conducted from 15 random points in each commune. Fifteen (15) investigators were hired for this work. The duration of this survey was one day per municipality. The total number of dogs to be found was a function of the number of dogs vaccinated per commune. A questionnaire was administered to dog owners in the vaccination area. Starting from 15 randomly defined points, the investigators systematically walked around the streets in search of families with at least one dog. 


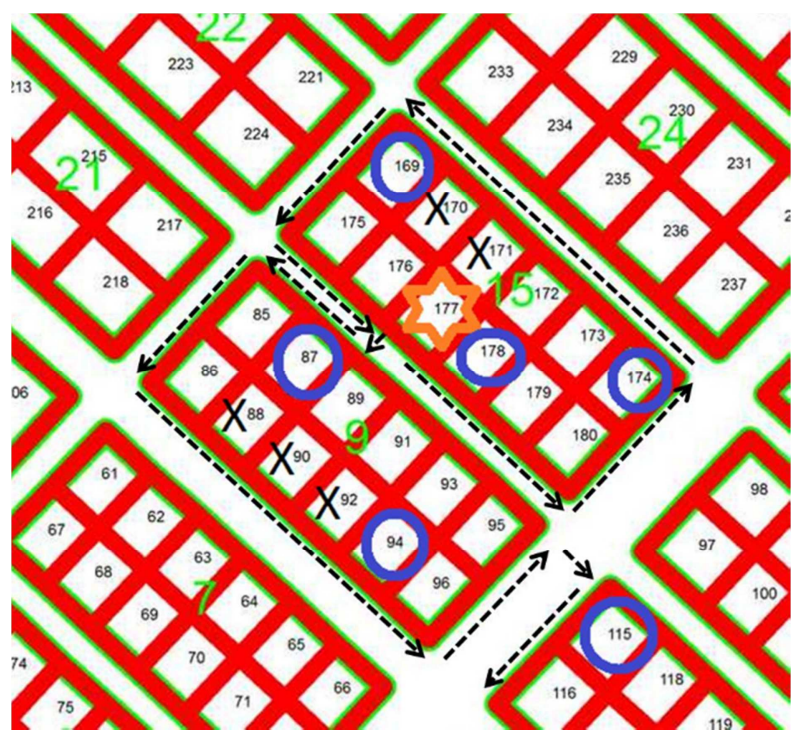

Figure 3. Guideline for the household survey strategy.

\subsection{Data Management and Statistical Methods}

The objective of this study is to evaluate the effectiveness of the vaccination campaign and ultimately to eliminate and control canine rabies. The data is saved in Microsoft Access 2010 software to be stored and imported into Microsoft Excel software for analysis. At each vaccination station, the number of vaccinated dogs is recorded daily. During the vaccination campaign, the total number of vaccinated dogs is determined by summing the number of vaccinated dogs from the different vaccination points. The Petersen-Bailey formula was used to determine the dog's dog number in the capturerecapture method of dogs: $N=M *(n+1) /(m+1)$ and the standard error was calculated by the following formula: Square root $M(n+1) *(n m) /(m+1) 2 *(m+2)$, where $n=$ number of untagged recaptured dogs in the household survey and $\mathrm{m}=$ number of recaptured dogs tagged in the household survey.

\section{Results and Discussion}

Table 1. Summary of data collected from vaccination posts, household survey, transect study and vaccination coverage estimated by the Bayesian model.

\begin{tabular}{|c|c|c|c|}
\hline & Commune V & Commune VI & Sénou \\
\hline & Nor $\%(n / N)$ & N or $\%(n / N)$ & Nor $\%(n / N)$ \\
\hline \multicolumn{4}{|l|}{ Data from vaccination points } \\
\hline Number of vaccination posts & 19 & 21 & 3 \\
\hline Number of dogs vaccinated & 429 & 784 & 410 \\
\hline \multicolumn{4}{|l|}{ Data from household survey } \\
\hline $\mathrm{N}$ dog identified during household survey & 364 & 591 & 314 \\
\hline Vaccinated dogs identified & $26 \%(93 / 364)$ & $22 \%(131 / 591)$ & $48 \%(152 / 314)$ \\
\hline Confined non vaccinated dogs & $45 \%(121 / 270)$ & $43 \%(197 / 457)$ & $3 \%(5 / 161)$ \\
\hline \multicolumn{4}{|l|}{ Data from transect survey } \\
\hline Average transect lenght $(\mathrm{Km})$ & 9,2 & 11,1 & ne \\
\hline Dogs identified & 29 & 74 & ne \\
\hline Dogs with collars identified & $21 \%(6 / 29)$ & $8 \%(6 / 74)$ & ne \\
\hline Recapture probability (range) & $0,007-0,5$ & $0,005-0,5$ & ne \\
\hline Bayesian estimates & Médiane (IQR) & Médiane (IQR) & \\
\hline Vaccination coverage owned dogs $(\%)$ & $27,8(23,5-33,7)$ & $22,3(19,4-26,2)$ & nd \\
\hline Vaccination coverage all dogs $(\%)$ & $26,8(22,5-32,5)$ & $20,4(16,2-24,4)$ & nd \\
\hline
\end{tabular}

The vaccination coverage was $27 \%$ and $20 \%$ respectively in the communes $\mathrm{V}$ and VI slightly higher than that of the first pilot campaign reported by [15] in commune I of the district of Bamako which was $18 \%$. These vaccine coverage is well below the WHO / OIE recommendations of 70\%.

Other vaccination campaigns in urban areas in Zambia reported by [16]; achieved a vaccination coverage of $16 \%$, and that obtained by [17] was $24 \%$ in three districts of Djamena. Immunization coverage given by [9] in N'Djamena in three different zones was $87 \%$ in Zone I, $71 \%$ in Zone II and $64 \%$ in Zone III. In contrast, [18] had an overall immunization coverage of $67.8 \%$ in Tanzania after four consecutive vaccination campaigns.

The proportion of dogs without owners was estimated at $2 \%$ and $8 \%$ respectively in communes $\mathrm{V}$ and VI compared to $9 \%$ in commune I [15], but few dogs were observed in the streets during the transect study confirming the results of [15] in commune I.

A confidence interval for the non-owner dog population was considered, but this had a limited impact on total vaccination coverage. It is important to note that sensitivity analysis of the Bayesian model revealed that the minimum probability of recapture was the most sensitive parameter. However, only the proportion of dogs without owners is sensitive to this parameter, while the proportion of vaccinated dogs remains relatively stable.

The evaluation of the effectiveness reached a level similar to that of the vaccination coverage, with a final effectiveness of $33 \%$ for commune $\mathrm{V}$ and of $28 \%$ for commune VI. The effectiveness evaluation based on the household survey showed similar results. In this study, vaccine efficacy was not a factor to consider. 
Availability, mainly the lack of information, has emerged as the key parameter of efficiency, as in the previous campaign conducted in commune I [15]. Despite the previous communication campaign using radio as the main channel, many dog owners said they did not get the information.

There may be a gap between community awareness of rabies and awareness of control measures. Therefore, awareness and information campaigns must clearly explain these measures to overcome mistrust.

TV ads may have reached additional households and should certainly be included in the future. In addition, since the participation rate was higher in neighborhoods where criers had been engaged, this communication channel or these speakers should be better used in a future campaign. Public posters hung in strategic places, such as health centers, schools or markets, could be more numerous (more than one poster per neighborhood).

Most often, the children brought the dog to the vaccination post confirming those reported by [16]. Some vaccinator teams have initiated door-to-door immunization, which has increased immunization coverage and efficacy, thereby supporting the results given by [17] who believe that this strategy could be effective in urban settings.

Missing information and awareness was the main reason. Compared to Ndjamena, neighborhood leaders were less engaged and did not push dog owners authoritatively to participate. Religion has not proven to be a reason for people to participate or not. On the one hand, this was not mentioned as an argument and, on the other hand, no statistically significant relationship could be found between religion and participation rate.

\section{Conclusion}

Despite a low final effectiveness $(33 \%$ in commune $\mathrm{V}$ and $28 \%$ in commune VI) and a vaccination coverage very clearly lower than $70 \%$ ). It was found, that it is possible to carry out mass vaccination campaigns of the dogs in the district of Bamako. Availability was identified as a key effectiveness parameter, strongly related to lack of campaign information. Therefore, a future intervention should focus on a strong information campaign through the different means of communication. As stated by several researchers, children are important when it comes to information transfer. School communication campaigns could be an effective strategy for increasing community awareness. Participatory stakeholders involving communities and local authorities will be needed to identify locally adapted vaccination strategies, perhaps through a combination of fixed-line vaccination and door-todoor vaccination.

Most of the reasons given by dog owners will be mitigated by some changes in the design of future vaccination campaigns. Community awareness of rabies and control measures will be clearly explained to overcome mistrust. Participatory stakeholders involving communities and local authorities will be needed to identify locally adapted vaccination strategies, perhaps through a combination of fixed-line vaccination and door-to-door vaccination. The development of an effective strategy based on the SARE approach (rabies elimination approach) would further increase the level of participation.

\section{References}

[1] Boegel, K et Meslin, FX, 1990. Economic Aspects of Eliminating Human and Canine Rabies: Principles for Program Orientation. Relation, 68 (4): 409-418.

[2] Hampson, K., Coudeville, L., Lembo, T., Sambo, M., Kieffer, A., Attlan, M., et al., 2015. Estimating the global burden of endemic canine rabies. PLoSNegl. Trop. Dis. 9.

[3] Knodel DL et al., 2005. Reassessment of the burden of rabies in Africa and Asia. Bulletin of the World Health Organization, 83: $360-368$.

[4] Morvan, J., september 2010, rabies; World Rabies Day. Rabies alert.

[5] Mérial., july 2006. Contagious diseases; rabies French National Veterinary Schools.

[6] Thiery, G; 1959. Particularités de la rage dans l'ouest africain. Bull. Epizoot. Dis. Afr. Volume 7, pages 265.

[7] Hampson, K., Coudeville, L., Lembo, T., Sambo, M., Kieffer, A., Attlan, M., et al., 2015. Estimating the global burden of endemic canine rabies. PLoSNegl. Trop. Dis. 9.

[8] AfroREB. Situation of rabies in Mali, september 2014.

[9] Kayali, U., Mindekem, R., Yemadji, N., Vounatsou, P., Kaninga, Y., Ndoutamia, AG et Zinsstag, J. 2003; Coverage of pilot parenteral vaccination campaign against canine rabies in N'djamena, chad. Bulletin of the World Health Organization, 81 (10): 739-744.

[10] Fevre, E. M. P., K.; Fyfe, J.; Waiswa, C.; Odiit, M.; Coleman, P. G.; Welburn, S. C., 2005. A burgeoning epidemic of sleeping sickness in Uganda. Lancet 366, 745-747.

[11] Mallewa M, Fooks AR, Banda D, Chikungwa P, Mankhambo $\mathrm{L}$, et al., 2007. Rabies encephalitis in malaria-endemic area, Malawi, Africa. Emerg Infect Dis; 13: 136-9.

[12] OMS 2010; vaccins antirabiques. Note d'information de l'OMS: Relevé épidémiologique hebdomadaire; volume 32 (85); pages 309-320.

[13] Dao, S., Abdillahi, A. M., Bougoudogo, F., Touré, K., Simbe, C., 2006. Aspects épidémiologiques de la rage humaine et animale dans la zone urbaine de Bamako, Mali. Bull. Soc. Pathol. Exot. 1990 (99), 183-186.

[14] RGPH-2009 (4th General Census of Population and Housing of Mali), 2009.

[15] Muthiani, Y., Traoré, A., Mauti, S., Zinsstag, J., Hattendorf, J., 2015. Low coverage ofcentral point vaccination against dog rabies in Bamako, Mali. Prev. Vet. Med. 120 (2), 203209 .

[16] De Balogh, K. K., Wandeler, A. I., Meslin, F. X., 1993. A dog ecology study in an urban and a semi-rural area of Zambia. Onderstepoort J Vet Res 60, 437-443. 
[17] Durr, S.; Mindekem, R; Kaninga, Y; Moto, D Doumagoum; Meltzer, MI; Vounatsou, P et Zinsstag, J. Epidemiol. Infect. 2009; Effectiveness of dog rabies vaccination programmes: comparison of owner-charged and free vaccination campaigns. 137, 1558-1567. Cambridge University.
[18] Cleaveland, $\mathrm{S}$ and Kaare, $\mathrm{M}$ and Tiringa, $\mathrm{P}$ and Mlengeya, $\mathrm{T}$ and Barrat, J; Elsevier 2003; A dog rabies vaccination campaign in rural Africa: impact on the incidence of dog rabies and human dog-bite injuries; vaccine; vol 21; 17-18; pages 1965-1973. 